This item was submitted to Loughborough's Research Repository by the author.

Items in Figshare are protected by copyright, with all rights reserved, unless otherwise indicated.

\title{
Performance enhancement and the young athlete: Mapping the landscape and navigating future directions
}

PLEASE CITE THE PUBLISHED VERSION

https://doi.org/10.1123/kr.2019-0026

\section{PUBLISHER}

Human Kinetics

\section{VERSION}

AM (Accepted Manuscript)

\section{PUBLISHER STATEMENT}

Accepted author manuscript version reprinted, by permission, from Kinesiology Review, 2020, 8(3), pp. 171 179, https://doi.org/10.1123/kr.2019-0026 @ Human Kinetics, Inc

\section{LICENCE}

CC BY-NC-ND 4.0

\section{REPOSITORY RECORD}

Harwood, Chris, and Sam Thrower. 2019. "Performance Enhancement and the Young Athlete: Mapping the Landscape and Navigating Future Directions". Loughborough University.

https://hdl.handle.net/2134/13234169.v1. 
7 Performance Enhancement and the Young Athlete: Mapping the Landscape and Navigating 8

\section{Future Directions}

Chris G. Harwood ${ }^{1}$ and Sam N. Thrower ${ }^{1,2}$

Loughborough University ${ }^{1}$

University of Roehampton ${ }^{2}$

Correspondence:

Correspondence concerning this article should be addressed to Chris G. Harwood, School of

8
Sport, Exercise \& Health Sciences, Loughborough University, Loughborough, United Kingdom, LE11 3TU. Tel: +44 01509 226342, Email: c.g.harwood@lboro.ac.uk 


\section{Abstract}

The aim of this paper is to provide a comprehensive narrative review of existing research that has advanced scientific knowledge in relation to the effectiveness of performance-enhancement based interventions within youth sport settings. Specifically, we explore the effects of psychological, social, and psychosocial interventions on sports performance with young athletes (18 years of age or under). Drawing upon over 80 published studies which have attempted to enhance young athletes' performances using a range of methodological and strategic approaches, we present four main clusters of research. These clusters include: (a)

Single strategy psychological skills training (PST) interventions; (b) multimodal PST interventions; (c) alternative single strategy interventions; and (d) alternative multimodal interventions. In each of these clusters, we map the landscape and highlight key papers of particular interest before drawing out critical reflections, future research directions, and recommendations for supporting further scholarship and practice with young athletes. Key Words: Narrative Review, Performance, Psychological Skills Training, Youth Sport. 
1 Performance Enhancement and the Young Athlete: Mapping the Landscape and Navigating

\section{Future Directions}

Within her seminal position paper over 30 years ago, Vealey (1988) defined psychological skills training (PST) as the techniques and strategies designed to teach or enhance mental skills that facilitate performance and a positive approach to sport competition. Whilst there has been a longstanding tendency to focus research efforts on studying elite, adult, or intercollegiate athletes (Tremayne \& Newbery, 2005), Vealey (1988) suggested that young athletes are:

More ripe for PST interventions than older athletes who have already internalised dysfunctional responses to competition. Thus, PST with younger athletes can be especially effective and rewarding as a means of helping youngsters develop appropriate psychological skills for sport competition (p.323).

Along these lines, researchers have since pointed out that young athletes who are introduced to PST at an early age are more likely to use sport psychology services than mature elite athletes (Blom, Hardy, Burke, \& Joyner, 2003). Scholars have also highlighted how young athletes are both capable of learning and applying psychological skills and are responsive to strategies to enhance their performance (Orlick \& McCaffrey, 1991; Lauer, Zakrajsek \& Lauer, 2016). Empirical research has illustrated how child-athletes as young as 10 years of age demonstrate a basic understanding of goal setting and imagery, whilst adolescent-athletes (13-15 years) show a more advanced awareness of the most commonly used psychological strategies (i.e., self-talk, imagery, relaxation, and goal setting; McCarthy, Jones, Harwood, \& Olivier, 2010). As such, it appears that youth sport is an ideal time to introduce young athletes to sport psychology and work with them to proactively develop the skills and techniques needed to optimise sport performance. The value placed on psychological techniques for young athletes extends implicitly to helping them to cope with the potential pressure of organised youth sport, and specifically the ongoing professionalization of talent development including sport-specific academies, 
1 performance centres, and pathway programmes. To this end, young athletes have become an

2 increasingly important client group for the sport psychology practitioner and a population whose

3 social, cognitive, and emotional development should be carefully considered by the practitioner

4 when delivering their services (Visek, Harris, \& Blom, 2009). There is subsequently additional

5 salience placed on the quality and scope of scientific research with young athletes that may

6 inform the work of the practitioner. Research on psychological interventions that influence

7 performance in young athletes is particularly imperative given that coaches have been found to

8 favour psychological services that offer returns around improved athlete performance or

9 performance consistency (Wrisberg, Loberg, Simpson, Withycombe \& Reed, 2010). However,

10 despite a growing number of intervention studies evaluating performance-enhancement based

11 interventions within youth sport, there is an absence of reviews which provide clear recommendations for supporting further scholarship and evidence-based practice within this area.

Taking these points into consideration, this current contribution to the Institute for the

14 Study of Youth Sport (ISYS) Special Issue reviews the existing research landscape that has

15 advanced knowledge of the effectiveness of performance-enhancement based interventions

16 within youth sport settings. Specifically, we explore the effects of psychological, social, and

17 psychosocial interventions on sports performance with young athletes. In line with definitions

18 of youth sport (Harwood \& Thrower, 2019), only studies including participants with a Mage of

1918 years or under were considered in this review. Specifically, a narrative review was

20 conducted by drawing upon search data made available to the authors (D. J. Brown, personal

21 communication, October 12, 2018) from a recent and extensive review of literature of psychological and psychosocial interventions on sport performance ( $>400$ studies) across

23 multiple age groups (see Brown \& Fletcher, 2017) and further searching of key sport

24 psychology-related journals (e.g., The Sport Psychologist, Journal of Sport and Exercise

25 Psychology, Journal of Applied Sport Psychology, Psychology of Sport and Exercise, Sport, 
1 Psychology, Journal of Sport Sciences) and databases (e.g., PsychINFO, PsychARTICLES,

2 SPORTDiscus). This process identified $>80$ published intervention studies ${ }^{1}$ reporting work that

3 has attempted to enhance young athletes' performances. Drawing upon this literature, we

4 provide insights into four overarching clusters of research (i.e., single strategy PST

5 interventions, multimodal PST interventions, alternative single strategy interventions,

6 alternative multimodal interventions; Rumbold, Fletcher, \& Daniels, 2012) that represent

7 varying methodologies and strategic approaches to investigating performance enhancement in

8 youth sport samples. In each section, we highlight key papers of particular interest in terms of

9 their methods before drawing out future research directions, challenges, and recommendations

10 for supporting further scholarship and practice in this important population.

Research Cluster 1: Single Strategy PST Interventions

A sizeable body of research has explored the effectiveness of traditional single (i.e.,

individual) strategy PST interventions on performance in young athletes. Studies have explored

the effectiveness of imagery (e.g., Fortes, Freitas-Júnior, Paes, Vieira, Nascimento-Júnior,

Araújo Lima-Júnior, \& Ferreira, 2018; Garza \& Feltz, 1998; Guillot, Genevois, Desliens,

Saieb, \& Rogowski, 2012; Post, Wrisberg, \& Mullins, 2010; Post, Muncie, \& Simpson, 2012), self-talk (e.g., Hatzigeorgiadis, Zourbanos, Goltsios, \& Theodorakis, 2008; Hatzigeorgiadis, Zourbanos, Mpoumpaki, \& Theodorakis, 2009; Johnson, Hrycaiko, Johnson, \& Halas, 2004; Ming \& Martin, 1996; Theodorakis, Weinberg, Natsis, Douma, \& Kazakas, 2000), relaxation (e.g., Haddad \& Tremayne, 2009; Lanning \& Hisanaga, 1983) and goal setting protocols (e.g., Pierce \& Burton, 1998) on a variety of performance-related indices.

Imagery

In the case of imagery-based interventions, findings have revealed mixed results in relation to its performance-related effectiveness. A number of studies have shown that imagery can improve coach-rated performance of athletes during figure skating competitions (e.g., 
1 et al., 2010), accuracy during a tennis serve task (Guillot et al., 2012; Guillot, Desliens, Rouyer,

2 \& Rogowski, 2013), and passing decision making during a simulated volleyball match (Fortes

3 et al., 2018). However, other studies have shown mixed findings (e.g., Post et al., 2012;

4 Munroe-Chandler, Hall, Fishburne, Murphy, \& Hall, 2012; Simonsmeier, Frank, Gubelmann,

5 \& Schneider, 2018) or no significant improvements in relation to performance (e.g.,

6 Björkstrand \& Jern, 2013; Kanthack, Bigliassi, Vieira, \& Altimari, 2014; Munroe-Chandler,

7 Hall, Fishburne, \& Shannon, 2005; Rodgers, Hall, \& Buckolz, 1991). However, a number of

8 these studies were reliant upon very brief interventions (i.e., 1-2 sessions; Björkstrand \& Jern,

9 2013; Kanthack et al., 2014).

10 Given the varied nature of these findings, it is important to highlight that there is some

11 initial evidence to suggest that imagery may be more effective for young athletes with higher

12 levels of expertise (Simonsmeier et al., 2018), for performing closed skilled tasks (i.e., tennis

13 serving; Coelho, De Campos, Silva, Okazaki, \& Keller, 2007), and when adopting an external

14 attentional focus (Guillot et al., 2013). Interestingly, studies have also suggested that cognitive

15 specific imagery may be more effective and more engaging for young children compared to

16 adolescents (Munroe-Chandler et al., 2012). Taking these points into consideration, future

17 research is needed to directly compare different types of imagery interventions (i.e., cognitive

18 specific (CS), cognitive general (CG), motivational general mastery (MG-M), motivational

19 general arousal (MC-A)) across different tasks, levels, and stages of development within the

20 context of youth sport.

21 Self-talk

A number of studies have explored the impact of self-talk interventions on young

23 athletes' performance (e.g., Hatzigeorgiadis et al., 2008; Hatzigeorgiadis et al., 2009;

24 Hatzigeorgiadis, Galanis, Zourbanos, \& Theodorakis, 2014; Johnson et al., 2004; Ming \&

25 Martin, 1996; Palmer, 1992; Theodorakis et al., 2000). This body of research has provided

26 support for the effectiveness of both motivational (e.g., Hatzigeorgiadis et al., 2008; 
1 Hatzigeorgiadis et al., 2009) and instructional self-talk (e.g., Johnson et al., 2004) intervention

2 strategies in different settings and conditions. Specifically, there is some evidence to suggest

3 that instructional self-talk, in the form of externally focused cues, may be more effective for

4 young athletes' performance than motivational or no self-talk (Theodorakis et al., 2000),

5 particularly during the early stages of learning (Zourbanos, Hatzigeorgiadis, Bardas, \&

6 Theodorakis, 2013). For instance, Zourbanos et al. (2013) compared the effects of self-talk on

7 dominant and nondominant arm performance on a handball shooting task. Findings revealed

8 that instructional and motivational self-talk both improved children's performance significantly

9 in comparison to a control group. However, instructional self-talk had a larger effect compared

10 to motivational self-talk for the nondominant arm.

11 Studies have also more recently started to explore the effects of self-talk on young

12 athletes' performance during competition. In an innovative and extended piece of field-based

13 intervention research, Hatzigeorgiadis and colleagues (2014) used a multiple comparison cross

14 subject design to examine the effectiveness of motivational and instructional self-talk on

15 percentage improvement in competitive swimming times. Forty-one adolescent competitive

16 swimmers $($ Mage $=14.52)$ were randomly assigned to an experimental $(n=21)$ or control

17 group $(n=20)$. Participants in the experimental group were consecutively introduced to a wide

variety of instructional (e.g., 'elbow', 'deep', 'ankles') and motivational cues (e.g., 'let's go

strong', 'power legs', 'give it all') and which were subsequently integrated and coached within

swimming training sessions. After both instructional and motivational self-talk phases, the participants were allowed to autonomously design a plan to use during training and competition during the remaining weeks. Following the 10 -week intervention, results showed that the intervention group had greater percentage performance improvements in competitive times than the control group. Interestingly (and of note to practitioners) when given the choice over selftalk type, the swimmers preferred to use motivational self-talk cues during competition. Such preferences are consistent with the notion that highly skilled athletes should avoid attempting to 
1 consciously control movements when performing during competition especially in high

2 pressure situations (i.e., Conscious Processing Hypothesis; Masters, 1992). Overall, the self-

3 talk literature offers some important considerations for practitioners working with young

4 athletes who are simultaneously learning skills and competing in high-pressured youth sport

5 settings. Further research which directly compares the efficacy of different types of self-talk

6 (i.e., instructional vs. motivational) across different conditions (i.e., skill acquisition, sport-

7 specific tasks, competition performances) would be a valuable contribution to the literature (see

8 Theodorakis et al., 2000 for an example).

\section{Relaxation}

In contrast to imagery and self-talk, relatively little academic attention has focused on

the use of relaxation as an individual intervention to enhance performance in young athletes. As

is illustrated in a forthcoming section, relaxation techniques are often combined with imagery as part of multimodal PST interventions. Despite this, there is some evidence to suggest that relatively brief (i.e., 1 x 20-minute session) and more extensive (i.e., 7 x 30-minute sessions) physical relaxation interventions (i.e., progressive muscular relaxation, breath control) can improve performance with both children (i.e., Haddad \& Tremayne, 2009) and adolescent athletes respectively (i.e., Lanning \& Hisanaga, 1983). For example, Haddad and Tremayne (2009) examined the effects of centering on free-throw basketball shooting performance of young athletes. Using a single subject multiple baseline design, five 10-11year old basketball players took part in a four-week intervention. The baseline period for all participants ranged from two to three weeks (i.e., two shooting sessions per week) and the intervention involved a single 20-minute session on the centering breath and accompanying educational-workbook activities. Shooting sessions resumed over the subsequent weeks to test the effectiveness of the intervention. Findings highlighted how implementation of the centering breath during the post intervention phase led to increases in successful free throw percentage across all participants with moderate to high degrees of percentage improvements. Notwithstanding these 
1 encouraging findings, what is often missing in these single interventions is actual consideration

2 of the type of symptoms that young athletes may experience and report (e.g., cognitive vs.

3 somatic anxiety) as well as their perceptions of these symptoms (i.e., facilitative vs. debilitate).

4 Such data may be important to process before implementing relaxation-based interventions

5 depending on the nature of the research question and the aim of the work (e.g., foundational

6 self-regulation skill vs. targeted anxiety management).

$7 \quad$ Goal Setting

Despite its widespread use as a tool to enhance performance with athletes there is, somewhat surprisingly, relatively little research which has examined the effectiveness of goal setting interventions on performance in youth sport. In one of the only interventions [to the

11 authors' knowledge] to be conducted with young athletes, Pierce and Burton (1998) investigated the impact of goal setting styles on a goal setting training programme for gymnasts. Adopting a quasi-experimental design, 25 female gymnasts $($ Mage $=13.10)$ participated in a goal setting training programme across an 8-week season. To investigate how goal-setting styles affected program effectiveness, gymnasts were subsequently categorized into goal-setting style groups (i.e., failure-orientated, success- orientated, performanceorientated high, and performance-orientated low). Although there are different scholarly perspectives on the nature of achievement goal orientations, performance-orientated versus success/failure-orientated goal setting styles broadly mirror the concepts of task versus ego orientation within Achievement Goal Theory (Nicholls, 1989). Findings highlighted how

21 performance-orientated (i.e., task orientated) gymnasts significantly improved competitive performance scores over time, whilst success-orientated (i.e., ego orientated) gymnasts showed a slight decrement. Results also highlighted how performance-orientated gymnasts reported higher perceptions of the goal setting training programme effectiveness and engagement with the processes. Although not conducted with young athletes per se, it is worth noting research with adolescent high school students has shown that setting difficult but realistic (Tenenbaum, 
1 Bar-Eli, \& Yaaron, 1999; Bar-Eli, Tenenbaum, Pie, Btesh, \& Almog, 1997) short and/or long

2 term goals (Tenenbaum, Pinchas, Elbaz, Bar-Eli, \& Weinberg, 1991) results in improved

3 performances on physical tasks in comparison to setting 'do-your-best' goals or no goals. In

4 summary, while goal setting as a strategy is often included alongside imagery, self-talk and/or

5 relaxation in multimodal interventions, it is curious that longitudinal studies focused on goal

6 setting and goal debriefing (e.g., goal performance review and reflection) in young athletes are

7 not more evident given potential impacts on self-regulated learning (Zimmerman, 2000).

\section{Research Cluster 2: Multimodal PST Interventions}

Multimodal interventions typically combine two or more different types of psychological techniques and strategies (e.g., imagery, goal setting, relaxation, self-talk) within a single intervention ${ }^{2}$. Such approaches have proven popular in the youth sport literature to date with scholars taking two distinctive methodological avenues. First, there is a substantive cluster of studies that have tested a range of different intervention combinations with young athletes to determine which single or multimodal combination is the most effective. Many of these studies have also employed a control group condition. Such effective combinations have included: Imagery and arousal regulation (i.e., Wrisberg \& Anshel, 1989), relaxation/centering and self-talk (i.e., Rogerson \& Hrycaiko, 2002), imagery, relaxation, and video observation (i.e., Li-Wei, Qi-Wei, Orlick, \& Zitzelsberger, 1992), video observation and motor imagery (i.e., Battagalia et al., 2014), and relaxation and imagery (i.e., Koehn, Morris, \& Watt, 2014). In one of the first studies to be conducted in this area, Wrisberg and Anshel (1989) examined the effectiveness of mental imagery and arousal regulation on young basketball players' (10-12 years) free throw shooting performance. During the intervention phase, one group learned and practiced imagery, a second group learned and practiced arousal regulation techniques, a third group practiced a combination of imagery and arousal regulation, while a control group were given no strategies. Mental imagery combined with arousal adjustment emerged as the most beneficial strategy on free throw shooting performance. Findings 
1 highlighted significant group effects and subsequent pairwise contrasts illustrated differences

2 between the combined group (Imagery and arousal) and the arousal alone and control group.

3 Similarly, Li-Wei et al. (1992) examined the effects of mental training on performance

4 enhancement with 7-10 year old table tennis players over an extended 6-month period.

5 Specifically, 40 children were assigned to one of three groups: (a) Imagery, relaxation, and

6 video observation of elite models; (b) video observation alone; or (c) a control group. Findings

7 revealed that children in the mental training group (i.e., Group A) experienced significantly

8 greater improvement in the accuracy and externally-rated technical quality of their shots than

9 children in the two other comparison groups.

Collectively, the (quasi) experimental studies in this cluster do point to the efficacy of combining two or more psychological strategies within interventions to facilitate performance enhancement with young athletes. Subsequent to this 'test the best combination' methodology, an alternative approach has been to examine the effectiveness of holistic multimodal PST packages on performances in young athletes. Such interventions typically include multiple psychological skills (i.e., imagery, relaxation, self-talk, goal setting) delivered over an extended period in the field with the view to equipping young athletes with a foundational 'tool box' of psychological strategies from which they can draw upon in training and competition. Encouragingly, research has provided sound support for the efficacy of PST packages on performance enhancement across a range of sports, levels, and developmental stages (e.g., Annesi, 1998; Atienza, Balaguer, \& Garcia Merita, 1998; Bar-Eli, Dreshman, Blumenstein, \&

21 Weinstein, 2002; Bar-Eli \& Blumenstein, 2004; Bell, Hardy, \& Beattie, 2013; Galloway, 2011;

22 Fournier, Calmels, Durand-Bush, \& Salmela, 2005; Mamassis \& Doganis, 2004; Sharp,

23 Woodcock, Holland, Cumming, \& Duda 2013; Sheard \& Golby, 2006; Wanlin, Hrycaiko, 24 Martin, \& Mahon, 1997). In a particularly effortful field-based design, Fournier and colleagues 25 (2005) explored the effects of a season long PST program on gymnastic performance and psychological skill development within an elite gymnastics academy. Adopting a multiple 
1 baseline single case design, 10 elite (i.e., national level) female gymnasts (Mage $=12.00)$

2 followed a five-step PST program consisting of relaxation (8 sessions), self-talk ( 5 sessions),

3 goal setting ( 3 sessions), focusing ( 4 sessions) and visualization ( 5 sessions) for 30 minutes per

4 week. These sessions were integrated into the weekly training schedule and delivered by one of

5 the coaches educated in sport psychology. Gymnasts training at a similar level academy in a

6 different locality formed a control group of participants. From self-reported data on

7 psychological skills development, the intervention was most effective on improving imagery

8 skills, relaxation, activation, focusing, and refocusing. Importantly, the gymnasts'

9 performances progressed 5\% more than a control group of gymnasts on three events (i.e., bars,

10 beam, floor). Similarly, Sheard and Golby (2006) examined the effect of a PST program on

11 swimming performance and psychosocial development. Thirty-six national level swimmers

$12 \quad($ Mage $=13.90)$ followed a seven-week intervention (i.e., five sessions on goal setting, visualisation, relaxation, concentration, and thought stopping) for 45 mins per week. Findings revealed significant self-reported improvements on a range of psychological indices (e.g., mental toughness, self-esteem, self-efficacy) as well as performance gains in 10 separate swimming events, three of which were statistically significant. interventions for young athletes. The popularity of such approaches may in part be due to the perceived advantages of introducing a broad spectrum of strategies in the anticipation of positive psychological outcomes and performance gains emerging from what is an important educational initiative in its own right for young people. However, this methodological approach is limited to the extent that it struggles to pinpoint what specific strategies of an intervention battery are most effective for young athletes in performance terms. In addition, these intervention methods are not fine grained enough to assist in deciphering under what organisational and environmental conditions and in what developmental stage (i.e., childhood, early adolescence, mid-adolescence) a particular strategy might be more or less efficacious. 


\section{Research Cluster 3: Alternative single strategy interventions}

In recent times, researchers have started to explore more novel and innovative psychological approaches (i.e., non-PST) to determine their effects on young athletes' performances. Popular single strategy interventions which have received attention in the youth sport literature include: Self-modelling (e.g., Ste-Marie, Rymal, Vertes, \& Martini, 2011; SteMarie, Vertes, Law, \& Rymal, 2013; Law \& Ste-Marie, 2005; Winfrey \& Weeks, 1993), music (e.g., Bishop, Karageorghis, \& Kinrade 2009; Eliakim, Meckel, Nemet, \& Eliakim, 2007), and mindfulness (e.g., Bernier, Thienot, Codron, \& Fournier, 2009; Bernier, Thienot, Pelosse, \& Fournier, 2014; Schwanhausser, 2009). Self-modelling is a form of modelling in which the content of the video displayed to the athlete is edited to only show examples of athletes' adaptive behaviour (i.e., positive performance highlights/executions; Dowrick, 1999). Despite an increasing number of studies exploring the impact of self-modelling on performance in young athletes, studies have shown mixed results (e.g., Ste-Marie et al., 2011; Law \& SteMarie, 2005; Ste-Marie et al., 2013; Winfrey \& Weeks, 1993). For instance, Ste-Marie et al. (2011) highlighted how 22 competitive gymnasts (Mage $=12.18)$ attained significantly higher beam scores when they viewed a self-modelling video versus when they did not over the course of a competitive season. However, other studies which have explored the impact of relatively brief (i.e., 3-6 weeks) self-modelling interventions have shown no significant difference on performance in figure skating jumps (Law \& Ste-Marie, 2005) and a gymnastic balance beam skill test (Winfrey \& Weeks, 1993). Despite these findings, with continuing technological advances and the potential for self-modelling to enhance self-efficacy, skill acquisition, and performance, we believe this is one area worthy of further academic attention.

Music-based interventions have also shown initial promise as interventions to enhance performance in young athletes. Specifically, there is some evidence to suggest that higher music intensity can increase arousal, improve choice reaction times (Bishop et al., 2009), and increase peak anaerobic power (Eliakim et al., 2007). Studies have also directly compared the 
1 effectiveness of music against other psychological strategies. For example, Miller and Donohue

2 (2003) examined the influence of two mental preparation interventions (i.e., music vs.

3 personalised motivational script) on 90 high school long distance runners. Participants

4 completed a $1.6 \mathrm{~km}$ baseline run and then were randomly assigned to one of three conditions

5 (i.e., listening to a personalized script of motivational and running technique statements on

6 headphones, listening to music on headphones, listening to no sound on headphones) three

7 minutes prior to a second time trial. Findings revealed how those who were assigned to the

8 motivational and running technique statement and music conditions significantly improved

9 their run performance, whilst participants in the no-sound control condition did not (Miller and

10 Donohue, 2003). Although research in this area is relatively limited, these initial findings

11 suggest that music is a simple, low-cost, and comparatively effective way of enhancing athletes' psychological preparation for competition.

More recently, researchers have started to explore mindfulness and acceptance-based interventions as methods of enhancing performance in young athletes. Mindfulness is considered as a mental state of consciousness in which one attends to present experience in all its sensorial, mental, cognitive and emotional aspects with an absence of judgement (Cottraux, 2007). Such approaches (often referred to as 'third wave') are becoming increasingly popular within the field of sport psychology and offer an alternative approach to some of the traditional cognitive-behavioral therapies which focus on controlling and limiting thoughts and emotions (see sections on self-talk and relaxation above). Whilst only a small number of studies have explored the effectiveness of mindfulness on performance in young athletes, these studies have shown initial promise (e.g., Bernier et al., 2009; Bernier et al., 2014; Schwanhausser, 2009).

23 For instance, building upon their earlier work, Bernier and colleagues (2014) examined the 24 effects and underlying processes of a season-long mindfulness-based intervention with seven 25 female figure skaters (Mage = 12.57). Findings from two case studies were presented and highlighted how the percentage improvement in national competition scores was much greater 
1 for those who followed the program than for a control group. In addition, the authors provided

2 valuable insights for practitioners regarding the design and delivery of mindfulness-based

3 interventions with young athletes to enhance their performance. Specifically, effective

4 processes were discussed in relation to the development of mindfulness skills (i.e., degree of

5 understanding key concepts and intention to develop skills) and the importance of committing

6 to mindfulness training. However, given the limited empirical work here, there remains a need

7 for more research which explores the applicability and efficacy of mindfulness-acceptance-

8 commitment (MAC; Gardner \& Moore, 2004) based approaches to performance enhancement

9 within youth sport (Bernier et al., 2009).

10 While currently more isolated examples of strategies employed in the literature, there is

11 also some preliminary evidence to suggest that interventions such as attributional retraining

12 (Miserandino, 1998), concurrent audio feedback (Baudry, Leroy, Thouvarecq, \& Chollet,

13 2006a), low intensity yoga practices (e.g., Donohue et al., 2006; Briegel-Jones, Knowles,

14 Eubank, Giannoulatos, \& Elliot, 2013), simulation training (Granda, Mingorance, Barbero,

15 Hinojo, Mohamed, \& Reyes, 2008), personal disclosure mutual sharing (Evans, Slater, Turner,

$16 \&$ Barker, 2013), and perceptual training (Farrow \& Abernethy, 2002; Murgia et al., 2014) can

17 improve performance in youth sport populations. One of the approaches that we believe has

18 particular potential for facilitating both skill acquisition and performance in young athletes is

19 perceptual training. Murgia and colleagues (2014) tested the effectiveness of perceptual

20 training on the anticipatory skills of soccer goalkeepers (i.e., predicting the direction of the ball

21 on penalty kicks). Forty-two skilled academy goalkeepers (Mage $=15.97)$ were randomly assigned to an experimental, placebo, or control condition. During the pre and post testing, those in the experimental group practiced with an interactive home-training video protocol with

24 feedback whilst those in the placebo condition watched televised penalty shootouts. Their results demonstrated the effectiveness of the home-training protocol, evidenced by significant accuracy improvements between pre-test and post-test seen only in the experimental group. 


\section{Research Cluster 4: Alternative multimodal interventions}

Building on the aforementioned single strategy approaches, a small number of studies have provided some support for the effectiveness of alternative (i.e., non-PST) multimodal interventions on performance. This includes investigations which have incorporated: Video

5 feedback packages (i.e., modelling, role play, instructions, video feedback, and coach feedback;

6 Hazen, Johnstone, Martin, \& Srikameswaran, 1990); verbal praise, video instructions, and

7 feedback (Anderson \& Kirkpatrick, 2002); combined self and expert modelling (Baudry, Leroy,

8 \& Chollet, 2006b); coping effectiveness training (i.e., cognitive therapy, relaxation, and

9 problem-solving; Reeves, Nicholls, \& McKenna, 2011); peer assessed feedback and goal

10 setting (Holt, Kinchin, \& Clarke, 2012); and holistic decision making programmes (i.e., video

11 feedback and questioning; García-González, Moreno, Gil, Moreno, \& Villar, 2014). In one particularly interesting study, Baudry and colleagues (2006b) investigated whether video modelling could enhance gymnasts' performance of the circle on a pommel horse. Sixteen national gymnasts $($ Mage $=14.30)$ were assigned to a modelling $(n=8)$ or control group $(n=$ 8). Those in the modelling group received multiple strategies, namely expert-modelling, selfmodelling, and feedback. After five sessions of training, results indicated that gains in the back, entry, front, and exit phases of the circle (i.e., body segmental alignment) were greater for the modelling group than for the control group (assessed via quantitative performance analysis on gymnastics performance). More recently, García-González et al. (2014) explored the effects of decision training on decision making and performance in young tennis players. Adopting a quasi-experimental design, 11 early adolescent tennis players were assigned to a control or experimental condition. Following a 10-week decision making program based on video feedback and questioning, those in the experimental condition significantly improved their

24 decision making and performance (i.e., skill execution) and crucially maintained performance improvements during the retention phase. 
As noted above, although research into more alternative and novel approaches to performance enhancement in young athletes is still in its infancy, these studies highlight the value of exploring visual, cognitive and auditory processes (e.g., through video, feedback, questioning, decision making) to engage young athletes in ecologically strong interventions that perhaps serve performance enhancement through improved skill acquisition.

\section{Critical Reflections, Future Directions and Practical Implications}

Reviewing the current body of scientific work in the area of performance enhancement and young athletes affords a number of critical observations as one takes a step back in order to look forwards. Firstly, despite claims regularly made within the literature about the lack of intervention studies with young athletes (e.g., Foster, Maynard, Butt \& Hays, 2016; Haddad \& Tremayne, 2009), we have located over 80 published studies which have directly examined the effectiveness of both traditional and more novel/alternative interventions on task-based or competition performance. Importantly, many of these studies have documented positive performance effects upon the athlete and highlighted how young athletes can benefit from a range of different psychological techniques and approaches. Nevertheless, with the exception of a few areas (e.g., imagery) there remains a lack of systematic depth of research on a given strategy that may inform age and stage appropriate guidelines for practitioners working with young athletes. In the absence of such guidelines, applied practitioners are encouraged to focus on the delivery of multimodal interventions (i.e., PST packages) due to their utility and reported effectiveness across a range of sports, levels, and developmental stages.

Secondly, there is an absence of coherent sport-specific research whereby practitioners or coaches from a specific sport (e.g., tennis; soccer) may be able to follow evidence-based scientific advice in a sport across the developmental spectrum (e.g., strategies for children, early, mid-adolescents etc). Although there are isolated studies attempting to advance knowledge around a specific strategy or set of approaches, there are not [as yet] an extensive number of applied researchers consistently dedicated to a specific area to build a genuine 
1 momentum. A logical starting point for such research is to identify which strategies are most

2 effective at optimising performance in specific sports (or sport-specific tasks) across different

3 stages of young athletes' development. Paying closer attention to developmental differences

4 would also provide important insights regarding the optimal age to introduce certain strategies

5 and how intervention delivery may differ based on the age of the child.

6 Thirdly, there is a sizeable body of literature reflecting practitioners' accounts and

7 experiences of working with young athletes (e.g., Foster et al., 2016; Henriksen, Larsen, Storm

8 \& Ryom, 2014; Howells, 2017), and such accounts offer a great deal of intimate, contextual

9 'craft knowledge' and process-oriented guidelines (see Visek et al., 2009 for the Youth Sport

10 Consulting Model) that may be pertinent for enhancing the quality of applied research.

11 Henriksen and colleagues (2014) offer the viewpoint that many studies are far removed from the reality of working in the field with young athletes. As such they propose that future research with youth athletes adheres to specific practical recommendations, namely (a) delivering a holistic skills package and helping athletes with the multitude of existential challenges involved in reaching the elite level; (b) taking the sport psychology service delivery to the athletes and involving key actors in their environment as much as possible in the intervention; and (c) fostering a long term development focus and following the athletes over an extended period.

Finally, many of the interventions in these studies are delivered by the research team and carefully controlled as much as is feasible. However, it is often unclear if those delivering the work are qualified as practitioners nor do many of the studies actively involve coaches or other significant stakeholders in the process of delivering interventions. Such methodological issues mark the challenge of the trade-off between controlled science and ecological reality whereby engagement with coaches or others may assist the extent to which intervention effects in a given environment are maintained beyond the initial empirical evaluation (see Hatzigeorgiadis et al., 2014 for a good example here). 
The critical observations above render this area of paediatric sport psychology at somewhat of a crossroads. On the one hand, there remains a sizeable dearth of investigations in this area that demand relevant scientific rigor and longitudinal dedication on behalf of the applied researcher. However, sparse government or research council funding for organised youth sport research creates difficulties for executing innovative, longitudinal designs to strengthen the evidence base. On the other hand, it may be feasible to gain accessibility and financial support from sports bodies/clubs and federations but only with a focus on research designs that afford less control and greater ecological sensitivity in order to meet the needs of the sport funder. In reconciling these challenges, we believe that applied researchers should appeal to the levels of responsibility and duty of care that organisations should have with respect to delivering performance enhancement interventions in their sport which are built on a clear evidence base. In this respect, the starting point is to highlight to organisations that more scientifically rigorous designs will yield more valid and robust information on developmentally appropriate strategies and techniques for young athletes, informing gold standard practice guidelines in the long term.

Over the past decade, driven by an interest in the application of ecological approaches (Bronfenbrenner, 2005) and the recognition that young athletes lie at the centre of complex social systems, researchers have focused on the quality of talent development environments (Henriksen, Stambulova, \& Roessler, 2010; Martindale, Collins, \& Daubney, 2005) and an understanding of the psychological characteristics for developing excellence (PCDEs; MacNamara, Button, \& Collins, 2010) in youth sport. Beyond a focus on performance outcomes and athletic improvement, scholarly attention has also deviated towards the study of life skills, positive youth development (PYD), and the psychosocial assets (see Holt et al., 2017) developed through organised youth sport participation. Such strengths-based approaches to developing the young person through sport are buoyed by salient societal issues around a duty of care to young athletes and topical concerns over athlete mental health (see Knight, Harwood, \& Gould, 2017). 
1 However, the development of such psychosocial skills is not conceptually divorced from impacts on performance, and there may be opportunities for researchers to investigate the degree to which psychosocial and life skill interventions improve performance as much as they influence psychological health and the quality of sport experience (see Harwood, 2008; Harwood, Barker \& Anderson, 2015).

In conclusion, there exists a promising body of evidence for the impact of traditional and contemporary psychological approaches on youth athlete performance, with a blend of innovative experimental and quasi-experimental, field-based studies. However, the volume and depth of research on psychological methods and strategies per se is lacking in terms of assisting in our understanding of what approaches work best for different developmental stages and within specific sport types. Single case research designs, qualitative evaluations of programmes (e.g., Sharp et al., 2013) and practitioner reflections (e.g., Henriksen et al., 2014; Howells, 2017) provide crucial insights into the complexity and challenging nature of working with young athletes. Such knowledge and knowhow on behalf of applied researchers and practitioners provide for opportunities to perhaps collaborate on executing longitudinal mixedmethods designs that facilitate developmentally sensitive examinations of specific strategies that can be delicately integrated within youth sport environments. Finally, we must remember as youth sport researchers that as much as we have a responsibility and duty of care towards the science of protecting young athletes and optimising health and well-being, we also have a responsibility to support those committed young people who are looking to scientists to serve their intrinsic passion for sport, and introduce them to the processes and skills that will help to optimise their performance and its consistency under pressure. At present, while we may be serving young athletes with anecdotal and experiential evidence of what works, we are falling short in scientific terms. 


\section{References}

*Anderson, G., \& Kirkpatrick, M. A. (2002). Variable effects of a behavioral treatment package on the performance of inline roller speed skaters. Journal of Applied Behavior Analysis, 35(2), 195-198.

*Annesi, J. J. (1998). Applications of the Individual Zones of Optimal Functioning model for the multimodal treatment of precompetitive anxiety. The Sport Psychologist, 12(3), $300-316$.

*Atienza, F.L., Balaguer, I., \& Garcia Merita, M.L. (1998). Video modeling and imaging training on performance of tennis serve of 9 to 12 year old children. Perceptual and Motor Skills, 87, 191-215.

*Battaglia, C., D’Artibale, E., Fiorilli, G., Piazza, M., Tsopani, D., Giombini, A., Calcagno, G., \& di Cagno, A. (2014). Use of video observation and motor imagery on jumping performance in national rhythmic gymnastics athletes. Human Movement Science, 38(2), 225-234. doi:10.1016/j.humov.2014.10.001

*Bar-Eli, M., \& Blumenstein, B. (2004). Performance enhancement in swimming: The effect of mental training with biofeedback. Journal of Science and Medicine in Sport, 7(4), 454464.

*Bar-Eli, M., Dreshman, R., Blumenstein, B., \& Weinstein, Y. (2002). The effect of mental training with biofeedback on the performance of young swimmers. Applied Psychology, 51(4), 567-581.

Bar-Eli, M., Tenenbaum, G., Pie, J. S., Btesh, Y., \& Almog, A. (1997). Effect of goal difficulty, goal specificity and duration of practice time intervals on muscular endurance performance. Journal of Sports Sciences, 15(2), 125-135.

*Baudry L, Leroy D, \& Chollet, D. (2006b). The effect of combined self- and expert-modelling on the performance of the double leg circle on the pommel horse. Journal of Sport Sciences, 24, 1055-1063. doi:10.1080/02640410500432243. 
1 *Baudry, L., Leroy, D., Thouvarecq, R., \& Chollet, D. (2006a). Auditory concurrent feedback benefits on the circle performed in gymnastics. Journal of Sports Sciences, 24(2), 149-

*Bell, J. J., Hardy, L., \& Beattie, S. (2013). Enhancing mental toughness and performance under pressure in elite young cricketers: A 2-year longitudinal intervention. Sport, Exercise, and Performance Psychology, 2(4), 281.

*Bernier, M., Thienot, E., Codron, R., \& Fournier, J. F. (2009). Mindfulness and acceptance approaches in sport performance. Journal of Clinical Sport Psychology, 3(4), 320-333.

*Bernier, M., Thienot, E., Pelosse, E., \& Fournier, J. F. (2014). Effects and underlying processes of a mindfulness-based intervention with young elite figure skaters: Two case studies. The Sport Psychologist, 28(3), 302-315.

*Bishop, D. T., Karageorghis, C. I., \& Kinrade, N. P. (2009). Effects of musically-induced emotions on choice reaction time performance. The Sport Psychologist, 23(1), 59-76.

*Björkstrand, S., \& Jern, P. (2013). Evaluation of an imagery intervention to improve penalty taking ability in soccer: A study of two junior girls teams. Nordic Psychology, 65(4), 290-305.

Blom, L. C., Hardy, C. J., Burke, K. L, and Joyner, A. B. (2003). High school athletes' perceptions of sport psychology and preferences for services. International Sports Journal, 7, 18-24.

*Briegel-Jones, R.M.H., Knowles, Z., Eubank, M.R., Giannoulatos, K., \& Elliot, D. (2013). A preliminary investigation into the effect of yoga practice on mindfulness and flow in elite youth swimmers. The Sport Psychologist, 27 (4), 349-359.

Bronfenbrenner, U. (2005). Making human beings human: Bioecological perspectives on human development. London: Sage.

Brown, D. J., \& Fletcher, D. (2017). Effects of psychological and psychosocial interventions on sport performance: A meta-analysis. Sports Medicine, 47(1), 77-99. 
1 *Coelho, R. W., De Campos, W., Silva, S. G. D., Okazaki, F. H. A., \& Keller, B. (2007). Imagery intervention in open and closed tennis motor skill performance. Perceptual and Motor Skills, 105(2), 458-468.

Cottraux, J. (2007). Thérapie cognitive et emotions: La troisième vague [Cognitive therapy and emotions: The third wave]. Paris: Elsevier Masson.

*Donohue, B., Miller, A., Beisecker, M., Houser, D., Valdez, R., Tiller, S., \& Taymar, T. (2006). Effects of brief yoga exercises and motivational preparatory interventions in distance runners: results of a controlled trial. British Journal of Sports Medicine, 40 (1), 60-3. doi:10.1136/bjsm.2005.020024.

Dowrick, P. W. (1999). A review of self-modelling and related interventions. Applied and Preventive Psychology, 8(1), 23-39.

*Eliakim, M., Meckel, Y., Nemet, D., \& Eliakim, A. (2007). The effect of music during warmup on consecutive anaerobic performance in elite adolescent volleyball players. International Journal of Sports Medicine, 28(04), 321-325.

*Evans, A. L., Slater, M. J., Turner, M. J., \& Barker, J. B. (2013). Using personal-disclosure mutual-sharing to enhance group functioning in a professional soccer academy. The Sport Psychologist, 27(3), 233-243.

*Farrow, D., \& Abernethy, B. (2002). Can anticipatory skills be learned through implicit video based perceptual training? Journal of Sports Sciences, 20(6), 471-485.

*Fortes, L. S., Freitas-Júnior, C. J., Paes, P. P., Vieira, L. F., Nascimento-Júnior, J. R. A, Araújo Lima-Júnior, D. R. A., \& Ferreira, M. E. C. (2018). Effect of an eight-week imagery training programme on passing decision-making of young volleyball players. International Journal of Sport and Exercise Psychology, 6, 1-9. doi:10.1080/1612197X.2018.1462229 
1 Foster, D., Maynard, I., Butt, J., \& Hays, K. (2016). Delivery of psychological skills training to youngsters. Journal of Applied Sport Psychology, 28, 62-77. doi:10.1080/10413200.2015.1063097

*Fournier, J. F., Calmels, C., Durand-Bush, N., \& Salmela, J. H. (2005). Effects of a seasonlong PST program on gymnastic performance and on psychological skill development. International Journal of Sport and Exercise Psychology, 3, 59-78. doi:10.1080/1612197X.2005.9671758

Gardner, F.L., \& Moore, Z.E. (2004). A Mindfulness-Acceptance-Commitment (MAC) based approach to performance enhancement: Theoretical considerations. Behavior Therapy, $35,707-723$.

*Galloway, S. M. (2011). The effect of biofeedback on tennis service accuracy. International Journal of Sport and Exercise Psychology, 9(3), 251-266.

*García-González, L., Moreno, A., Gil, A., Moreno, M. P., \& Villar, F. D. (2014). Effects of decision training on decision making and performance in young tennis players: An applied research. Journal of Applied Sport Psychology, 26(4), 426-440.

*Garza, D. L., \& Feltz, D. L. (1998). Effects of selected mental practice on performance, selfefficacy, and competition confidence of figure skaters. The Sport Psychologist, 12(1), 115.

*Granda, V., Mingorance, E., Barbero, Á., Hinojo, S., Mohamed, M., \& Reyes, D. (2008). Effects of an additional computer simulation training programme and/or on-court specific instructions on advance cue detection in basketballers. International Journal of Sport Psychology, 39(3), 257-277.

*Guillot, A., Desliens, S., Rouyer, C., \& Rogowski, I. (2013). Motor imagery and tennis serve performance: The external focus efficacy. Journal of Sports Science \& Medicine, 12(2), 332. 
1 *Guillot, A., Genevois, C., Desliens, S., Saieb, S., \& Rogowski, I. (2012). Motor imagery and 'placebo-racket effects' in tennis serve performance. Psychology of Sport and Exercise, 13(5), 533-540.

*Haddad, K., \& Tremayne, P. (2009). The effects of centering on the free-throw shooting performance of young athletes. The Sport Psychologist, 23, 118-136.

Harwood, C.G., (2008). Developmental consulting in a professional football academy: The 5Cs coaching efficacy program. The Sport Psychologist, 22(1), 109-133.

Harwood, C. G., Barker, J. B., \& Anderson, R. (2015). Psychosocial development in youth soccer players: Assessing the effectiveness of the 5Cs intervention program. The Sport Psychologist, 29(4), 319-334.

Harwood, C.G., \& Thrower, S.N. (2019). Youth Sport. In D. Hackfort, R. Schinke, \& B. Strauss (Eds.), Dictionary of Sport Psychology. London: Elsevier.

*Hatzigeorgiadis, A., Galanis, E., Zourbanos, N., \& Theodorakis, Y. (2014). Self-talk and competitive sport performance. Journal of Applied Sport Psychology, 26(1), 82-95.

*Hatzigeorgiadis, A., Zourbanos, N., Goltsios, C., \& Theodorakis, Y. (2008). Investigating the functions of self-talk: The effects of motivational self-talk on self-efficacy and performance in young tennis players. The Sport Psychologist, 22(4), 458-471.

*Hatzigeorgiadis, A., Zourbanos, N., Mpoumpaki, S., \& Theodorakis, Y. (2009). Mechanisms underlying the self-talk-performance relationship: The effects of motivational self-talk on self-confidence and anxiety. Psychology of Sport and Exercise, 10(1), 186-192.

*Hazen, A., Johnstone, C., Martin, G. L., \& Srikameswaran, S. (1990). A videotaping feedback package for improving skills of youth competitive swimmers. The Sport Psychologist, 4(3), 213-227.

Henriksen, K., Larsen, C. H., Storm, L. K., \& Ryom, K. (2014). Sport psychology interventions with young athletes: The perspective of the sport psychology practitioner. Journal of Clinical Sport Psychology, 8, 245-260. doi:10.1123/jcsp.2014-0033 
1 Henriksen, K., Stambulova, N., \& Roessler, K. K. (2010). Holistic approach to athletic talent development environments: A successful sailing milieu. Psychology of Sport and Exercise, 11(3), 212-222.

*Holt, J. E., Kinchin, G., \& Clarke, G. (2012). Effects of peer-assessed feedback, goal setting and a group contingency on performance and learning by 10-12-year-old academy soccer players. Physical Education \& Sport Pedagogy, 17(3), 231-250.

Holt, N.L., Neely, K.C., Slater, L.G., Camiré, M., Côté, J., Fraser-Thomas, J., MacDonald, D., Strachan, L., \& Tamminen, K.A. (2017). A grounded theory of positive youth development through sport based on results from a qualitative meta-study. International Review of Sport and Exercise Psychology, 10(1), 1-49.

Howells, K. (2017). Butterflies, magic carpets, and scary wild animals: An intervention with a young gymnast. Case Studies in Sport and Exercise Psychology, 1, 26-37. doi:10.1123/cssep.2016-006

*Johnson, J. J. M., Hrycaiko, D. W., Johnson, G. V., \& Halas, J. M. (2004). Self-talk and female youth soccer performance. The Sport Psychologist, 18, 44-59.

*Kanthack, T. F. D., Bigliassi, M., Vieira, L. F., \& Altimari, L. R. (2014). Acute effect of motor imagery on basketball players' free throw performance and self-efficacy. Revista Brasileira de Cineantropometria \& Desempenho Humano, 16(1), 47-57.

Knight, C. J., Harwood, C.G., \& Gould, D. (2017). Introduction to working with young athletes. In C.J. Knight, C.G. Harwood, \& D. Gould (Eds). Sport psychology for young athletes (pp. 1- 6). Abingdon, Oxon: Routledge.

*Koehn, S., Morris, T., \& Watt, A. P. (2014). Imagery intervention to increase flow state and performance in competition. The Sport Psychologist, 28(1), 48-59.

*Lanning, W., \& Hisanaga, B. (1983). A study of the relation between the reduction of competition anxiety and an increase in athletic performance. International Journal of Sport Psychology, 14(4), 219-227. 
1 Lauer, E.E., Zakrajsek, R.A., \& Lauer, L. (2017). The role of sport psychology for young athletes. In C.J.Knight, C.G. Harwood, \& D. Gould (Eds). Sport psychology for young athletes (pp. 1- 6). Abingdon, Oxon: Routledge.

*Law, B., \& Ste-Marie, D. M. (2005). Effects of self-modeling on figure skating jump performance and psychological variables. European Journal of Sport Science, 5(3), 143-152.

*Li-Wei, Z., Qi-Wei, M., Orlick, T., \& Zitzelsberger, L. (1992). The effect of mental-imagery training on performance enhancement with 7-10 year old children. The Sport Psychologist, 6, 230-241.

MacNamara, Á., Button, A., \& Collins, D. (2010). The role of psychological characteristics in facilitating the pathway to elite performance part 1: Identifying mental skills and behaviors. The Sport Psychologist, 24(1), 52-73.

*Mamassis, G., \& Doganis, G. (2004). The effects of a mental training program on juniors precompetitive anxiety, self-confidence, and tennis performance. Journal of Applied Sport Psychology, 16(2), 118-137.

Martindale, R. J., Collins, D., \& Daubney, J. (2005). Talent development: A guide for practice and research within sport. Quest, 57(4), 353-375.

Masters, R. S. (1992). Knowledge, nerves and know-how: The role of explicit versus implicit knowledge in the breakdown of a complex motor skill under pressure. British Journal of Psychology, 83(3), 343-358.

McCarthy, P. J., Jones, M. V., Harwood, C. G., \& Olivier, S. (2010). What do young athletes implicitly understand about psychological skills? Journal of Clinical Sport Psychology, 4,158-172. doi:10.1123/jcsp.4.2.158

*Miller, A, \& Donohue, B. (2003). The development and controlled evaluation of athletic mental preparation strategies in high school distance runners. Journal of Applied Sport Psychology, 15, 321-334. doi:10.1080/10413200390238004. 
1 *Ming, S., \& Martin, G. (1996). Single-subject evaluation of a self-talk package for improving figure skating performance. The Sport Psychologist, 10(3), 227-238.

*Miserandino, M. (1998). Attributional retraining as a method of improving athletic performance. Journal of Sport Behavior, 21(3), 286.

*Munroe-Chandler, K. J., Hall, C. R., Fishburne, G. J., Murphy, L., \& Hall, N. D. (2012). Effects of a cognitive specific imagery intervention on the soccer skill performance of young athletes: Age group comparisons. Psychology of Sport and Exercise, 13, 324331.

*Munroe-Chandler, K. J., Hall, C. R., Fishburne, G. J., \& Shannon, V. (2005). Using cognitive general imagery to improve soccer strategies. European Journal of Sport Science, 5(1), 41-49.

*Murgia, M., Sors, F., Muroni, A.F., Ilaria, S., Prpic, V., Galmonte, A., \& Agostini, T. (2014). Using perceptual home training to improve anticipation skills of soccer goalkeepers. Psychology of Sport and Exercise, 15 (6), 642-648. doi:10.1016/j.psychsport.2014.07.009.

Nicholls, J.G. (1984). Achievement motivation: Conceptions of ability, subjective experience, task choice, and performance. Psychological Review, 91, 328-346.

Orlick, T., \& McCaffrey, N. (1991). Mental Training with Children for Sport and Life. The Sport Psychologist, 5, 322-334.

*Palmer, S. (1992). A comparison of mental practice techniques as applied to developing competitive figure skater. The Sport Psychologist, 6(2), 148-155.

*Pierce, B. E., \& Burton, D. (1998). Scoring the perfect 10: Investigating the impact of goalsetting styles on a goal-setting program for female gymnasts. The Sport Psychologist, 12(2), 156-168. 
1 *Post, P. G., Muncie, S., \& Simpson, D. (2012). The effects of imagery training on swimming performance: An applied investigation. Journal of Applied Sport Psychology, 24(3), $323-337$.

*Post, P. G., Wrisberg, C. A., \& Mullins, S. (2010). A field test of the influence of pre-game imagery on basketball free throw shooting. Journal of Imagery Research in Sport and Physical Activity, 5(1),

*Reeves, C. W., Nicholls, A. R., \& McKenna, J. (2011). The effects of a coping intervention on coping self-efficacy, coping effectiveness, and subjective performance among adolescent soccer players. International Journal of Sport and Exercise Psychology, 9(2), 126-142.

*Rodgers, W., Hall, C., \& Buckolz, E. (1991). The effect of an imagery training program on imagery ability, imagery use, and figure skating performance. Journal of Applied Sport Psychology, 3(2), 109-125.

*Rogerson, L. J., \& Hrycaiko, D. W. (2002). Enhancing competitive performance of ice hockey goaltenders using centering and self-talk. Journal of Applied Sport Psychology, 14(1), 14-26.

Rumbold, J. L., Fletcher, D., \& Daniels, K. (2012). A systematic review of stress management interventions with sport performers. Sport, Exercise, and Performance Psychology, 1(3), 173.

*Schwanhausser, L. (2009). Application of the mindfulness-acceptance-commitment (MAC) protocol with an adolescent springboard diver. Journal of Clinical Sport Psychology, 3(4), 377-395.

*Sharp, L.A., Woodcock, C., Holland, M. J. G., Cumming, J., \& Duda, J. L. (2013). Qualitative evaluation of the effectiveness of a mental skills training program for youth athletes. The Sport Psychologist, 27, 219-232. doi:10.1123/tsp.27.3.219 
1 *Sheard, M., \& Golby, J. (2006). Effect of a psychological skills training program on swimming performance and positive psychological development. International Journal of Sport and Exercise Psychology, 4(2), 149-169.

*Simonsmeier, B. A., Frank, C., Gubelmann, H., \& Schneider, M. (2018). The effects of motor imagery training on performance and mental representation of 7- to 15-year-old gymnasts of different levels of expertise. Sport, Exercise, and Performance Psychology, 7(2), 155-168. http://dx.doi.org/10.1037/spy0000117

*Ste-Marie, D. M., Rymal, A., Vertes, K., \& Martini, R. (2011). Self-modeling and competitive beam performance enhancement examined within a self-regulation perspective. Journal of Applied Sport Psychology, 23(3), 292-307.

*Ste-Marie, D. M., Vertes, K. A., Law, B., \& Rymal, A. M. (2013). Learner-controlled selfobservation is advantageous for motor skill acquisition. Frontiers in Psychology, 3, 556.

Tenenbaum, G., Bar-Eli, M., \& Yaaron, M. (1999). The dynamics of goal-setting: interactive effects of goal difficulty, goal specificity and duration of practice time intervals. International Journal of Sport Psychology, 30(3), 325-338.

Tenenbaum, G., Pinchas, S., Elbaz, G., Bar-Eli, M., \& Weinberg, R. (1991). Effect of goal proximity and goal specificity on muscular endurance performance: A replication and extension. Journal of Sport and Exercise Psychology, 13(2), 174-187.

*Theodorakis, Y., Weinberg, R., Natsis, P., Douma, I., \& Kazakas, P. (2000). The effects of motivational versus instructional self-talk on improving motor performance. The Sport Psychologist, 14(3), 253-271.

Tremayne, P., \& Newbery, G. (2005). Mental skill training program for children. In D. Hackfort, R. Lidor, \& J. Duda (Eds.), Handbook of research in applied sport psychology (pp. 93-106). Morgantown, WV: Fitness Information Technology. 
1 Visek, A. J., Harris, B. S., \& Blom, L. C. (2009). Doing sport psychology: A youth sport consulting model for practitioners. The Sport Psychologist, 23, 271-291. doi:10.1123/tsp.23.2.271

Vealey, R.S. (1988). Future directions in psychological skills training. The Sport Psychologist, 2, 318-336. doi:10.1123/tsp.2.4.318

*Wanlin, C. M., Hrycaiko, D. W., Martin, G. L., \& Mahon, M. (1997). The effects of a goalsetting package on the performance of speed skaters Journal of Applied Sport Psychology, 9, 212- 228.

*Winfrey, M. L., \& Weeks, D. L. (1993). Effects of self-modeling on self-efficacy and balance beam performance. Perceptual and Motor Skills, 77(3), 907-913.

*Wrisberg, C.A., \& Anshel, M.H. (1989). The effect of cognitive strategies on the free throw shooting performance of young athletes. The Sport Psychologist, 3, 95-104.

Wrisberg, C., Loberg, L., Simpson, D., Withycombe, J., \& Reed, A. (2010). An exploratory investigation of NCAA Division-I coaches' support of sport psychology consultants and willingness to seek mental training services. The Sport Psychologist, 24, 489-503.

Zimmerman, B.J. (2000). Attainment of self-regulation: A social cognitive perspective. In M. Boekaerts, P.R. Pintrich, \& M. Zeidner (Eds.), Handbook of self-regulation (pp. 13-39). San Diego, CA: Academic Press.

*Zourbanos, N., Hatzigeorgiadis, A., Bardas, D., \& Theodorakis, Y. (2013). The effects of selftalk on dominant and nondominant arm performance on a handball task in primary physical education students. The Sport Psychologist, 27(2), 171-176.

\section{Footnotes}

$23{ }^{1}$ Studies included in the review are identified with $\mathrm{a} *$ in the reference list.

$24{ }^{2}$ Interventions which combined one PST strategy and one alternative strategy were included in 25 this cluster. 